\title{
Hyaluronate increases intraocular pressure when used in cataract extraction
}

\author{
MICHAEL S PASSO, ${ }^{* 1}$ J TERRY ERNEST,' AND THOMAS K GOLDSTICK ${ }^{2}$
}

From the 'Department of Ophthalmology, University of Illinois at Chicago, Eye and Ear Infirmary, and the ${ }^{2}$ Department of Chemical Engineering, Northwestern University, Evanston, Illinois, USA

SUMMARY A prospective randomised study of 26 eyes ( 24 patients) following uncomplicated intracapsular cataract surgery was carried out with three groups in which different agents were used to re-form the anterior chamber: air, seven eyes; sodium hyaluronate, seven eyes; and a combination of hyaluronate plus systemic acetazolamide, 12 eyes. The intraocular pressure (IOP) was measured by Goldmann applanation tonometry 16 hours before surgery and every eight hours after surgery for 72 hours. The IOP doubled in the two hyaluronate-treated groups for the first day following cataract surgery. By contrast, the IOP in the group receiving air initially decreased slightly. Throughout the study the effect of using acetazolamide was never statistically significant. After the first day and a half the differences in IOP among the three treatment groups disappeared, and the pressures returned to their preoperative values.

Healon is a highly purified, high molecular weight fraction of sodium hyaluronate.' There is evidence that hyaluronate protects the corneal endothelium during anterior segment surgery, and the agent is in wide use. ${ }^{2-4}$ While some investigators have found it to be associated with increased IOP, $\leqslant-7$ others have found it not or only rarely to be so. ${ }^{\text {.110 }}$ We report the results of a prospective randomised study of patients undergoing cataract surgery with and without the use of hyaluronate and a third group with hyaluronate plus acetazolamide.

\section{Patients and methods}

Routine uncomplicated intracapsular cataract surgery was performed on 26 eyes of 24 patients by four surgical residents between September 1980 and February 1981. The patients were the first 24 consecutive ones without a past or family history of glaucoma, inflammatory ocular disease, or preoperative intraocular pressure (IOP) greater than $20 \mathrm{mmHg}$. The assignment to the three groups was

*Present address: Department of Ophthalmology, Oregon Health Sciences University, Portland, Oregon 97201, USA.

Correspondence to J Terry Ernest, MD, Department of Ophthalmology, University of Illinois at Chicago, Eye and Ear Infirmary, 1855 West Taylor Street, Chicago, Il 60612, USA. random except for six patients receiving intraocular lens implantation, who were all treated with hyaluronate plus acetazolamide. Any patient receiving medication necessary for other medical purposes was maintained on that therapy throughout the study or excluded because of possible pharmacological effects on IOP (e.g., corticosteroids, propranolol, etc.). All patients received retrobulbar anaesthesia followed by digital compression of the globe. A fornix-based conjunctival flap was made, followed by a step incision. After peripheral iridectomy, cryoextraction of the lens was performed with the aid of $1 \mathrm{ml}$ of 1:5000 dilution of alpha-chymotrypsin. The two hyaluronate-treated groups received $0.1 \mathrm{ml}$ of Healon to re-form the anterior chamber prior to closure with interrupted 10-0 nylon. Air was used to re-form the anterior chamber in the third group. All intraocular lenses were of the 4-loop, iris fixation type (Intermedics) and were coated with Healon prior to insertion.

The IOPs were determined by Goldmann applanation tonometry about 16 hours before surgery, approximately eight hours $(7 \cdot 1 \pm 1 \cdot 8$, mean \pm SD) postoperatively, and every eight hours thereafter for 72 hours. Each patient's preoperative IOP was used as his or her own control value.

Several statistical analyses were performed on the IOP data. A two-tailed Student's $t$ test was done on 572 
the mean difference between each IOP after surgery and its preoperative control. These means were also compared in pairs by the $t$ test. In addition analysis of variance was performed on these means for all three groups at each time. To test the variation in the ratio of males to females in the three treatment groups, $\chi^{2}$ analysis was performed. In both the analysis of variance and the $t$ test used to compare the means from different groups the variances of the means were tested for homogeneity by Levene's test for equal variance. Except when these variances differed $(p<0 \cdot 01)$, the variances within groups were obtained from the pooled data. This could be done in all $t$ tests comparing hyaluronate with and without acetazolamide and throughout the analysis of variance. A p value of 0.01 was used for statistical significance.

\section{Results}

The preoperative values for the three treatment groups are given in Table 1 . There was no statistically significant difference between their age, sex, and IOP.

In one of the patients who had both eyes operated on, the two eyes were randomly distributed to different treatment groups. In this patient the IOP was dramatically raised in the eye receiving hyaluronate but was decreased somewhat in the fellow eye receiving air (Fig. 1). The preoperative control data points shown at time zero were measured 16 hours preoperatively and were used as a constant.

In both the hyaluronate and hyaluronate plus acetazolamide groups the mean difference in IOP from preoperative values was significantly raised during the first two days postoperatively (Table 2 and
Table 1 Preoperative control values for the three treatment groups

\begin{tabular}{|c|c|c|c|}
\hline & \multicolumn{3}{|l|}{ Group } \\
\hline & Air & Hyaluronate & $\begin{array}{l}\text { Hyaluronate and } \\
\text { acetazolamide }\end{array}$ \\
\hline Number of eyes & 7 & 7 & 12 \\
\hline $\begin{array}{c}\text { Mean patient age } \\
\text { (years } \pm \text { SD) }\end{array}$ & $59 \cdot 9 \pm 10 \cdot 9$ & $65 \cdot 4 \pm 11 \cdot 1$ & $66 \cdot 8 \pm 9 \cdot 5$ \\
\hline Male/female & $2 / 5$ & $3 / 4$ & $7 / 5$ \\
\hline $\begin{array}{c}\text { Intraocular pressure } \\
(\mathrm{mmHg} \pm \mathrm{SD})\end{array}$ & $16 \cdot 7 \pm 1 \cdot 9$ & $17 \cdot 3 \pm 1 \cdot 9$ & $16 \cdot 0 \pm 2 \cdot 3$ \\
\hline
\end{tabular}

Fig. 2). The increase was greatest around 16 hours and almost doubled the IOP during the first postoperative day. Thereafter a gradual decline was seen, with no statistical significance after about a day and a half. In the group receiving air an initial decrease in this mean IOP difference was seen at eight hours. Thereafter this difference was no longer significant. A comparison of the mean differences with and without acetazolamide ( $t$ test) indicated no effect of the acetazolamide $(p>0 \cdot 2)$. After about the first day and a half there was no statistically significant IOP difference among any of the groups (analysis of variance) or between them and their preoperative control values (paired $t$ test).

Of the 12 patients receiving hyaluronate and acetazolamide six received intraocular lenses coated with Healon and six received routine, uncomplicated intracapsular cataract extraction. These two groups were not statistically different and their data were therefore pooled. This finding is in agreement with previous studies."

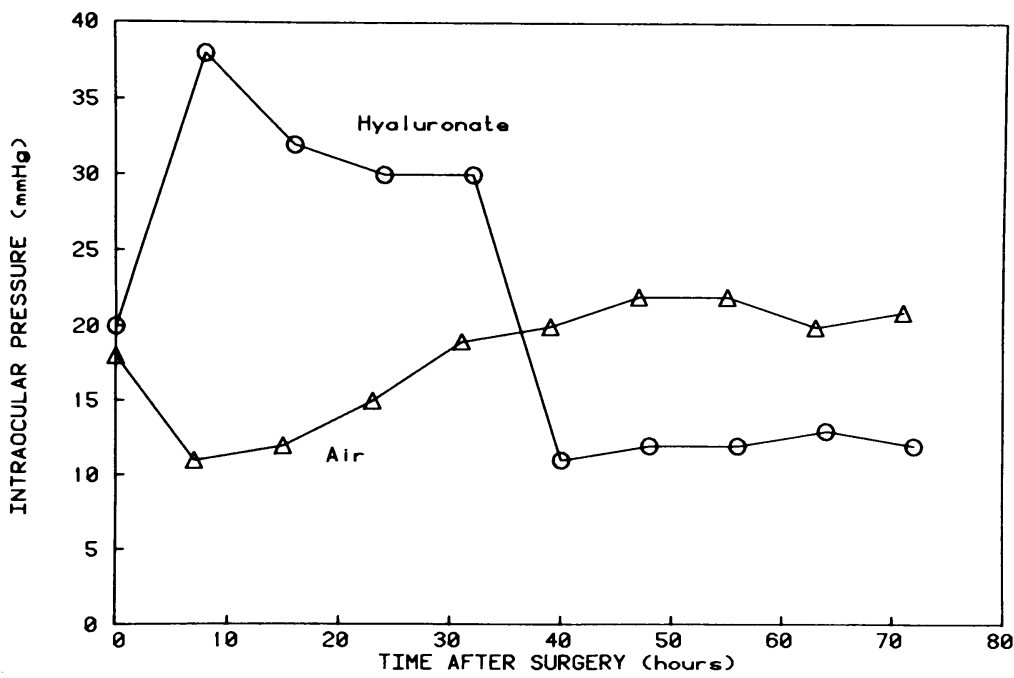

Fig. 1 The IOP in two eyes of the same patient. Cataracts were extracted from both eyes of this patient but they were placed in separate treatment groups. The anterior chamber of one eye was reformed with hyaluronate and the fellow eye with air. The preoperative control IOP was actually measured 16 hours before surgery. 
Table 2 Mean difference between the intraocular pressure and its preoperative control value $(\mathrm{mmHg} \pm S E)$

\begin{tabular}{lrrr}
\hline $\begin{array}{l}\text { Time afteranterior } \\
\text { chamber re-formed } \\
\text { (hours) }\end{array}$ & Air & Hyaluronate & $\begin{array}{l}\text { Hyaluronate and } \\
\text { acetazolamide }\end{array}$ \\
\hline 8 & $-6 \cdot 6 \pm 0 \cdot 8^{*}$ & $14 \cdot 9 \pm 2 \cdot 4^{*}$ & $15 \cdot 3 \pm 2 \cdot 6^{*}$ \\
16 & $-2 \cdot 0 \pm 2 \cdot 1$ & $16 \cdot 7 \pm 1 \cdot 1^{*}$ & $16 \cdot 8 \pm 2 \cdot 5^{*}$ \\
24 & $-0 \cdot 1 \pm 1 \cdot 8$ & $13 \cdot 1 \pm 1 \cdot 8^{*}$ & $12 \cdot 6 \pm 2 \cdot 7^{*}$ \\
32 & $1 \cdot 4 \pm 1 \cdot 4$ & $11.9 \pm 2 \cdot 1^{*}$ & $7 \cdot 9 \pm 2 \cdot 3^{*}$ \\
40 & $2 \cdot 3 \pm 1 \cdot 5$ & $7 \cdot 1 \pm 3 \cdot 6$ & $5 \cdot 8 \pm 2 \cdot 1$ \\
48 & $3 \cdot 3 \pm 1 \cdot 6$ & $4 \cdot 6 \pm 3 \cdot 1$ & $4 \cdot 5 \pm 2 \cdot 1$ \\
56 & $4 \cdot 0 \pm 1 \cdot 5$ & $2 \cdot 6 \pm 2 \cdot 4$ & $2 \cdot 8 \pm 1 \cdot 7$ \\
64 & $3 \cdot 7 \pm 1 \cdot 5$ & $1 \cdot 7 \pm 2 \cdot 0$ & $2 \cdot 0 \pm 1 \cdot 5$ \\
72 & $3 \cdot 6 \pm 1.1$ & $0 \cdot 7 \pm 1 \cdot 9$ & $1 \cdot 7 \pm 1 \cdot 5$ \\
& & & \\
Day 1 mean & $-2.9 \pm 1 \cdot 4$ & $14 \cdot 9 \pm 1 \cdot 2^{*}$ & $14 \cdot 9 \pm 2 \cdot 5^{*}$ \\
Day 2 mean & $1 \cdot 7 \pm 1 \cdot 5$ & $9 \cdot 2 \pm 2 \cdot 5^{*}$ & $7 \cdot 9 \pm 2 \cdot 1^{*}$ \\
Day 3 mean & $3 \cdot 6 \pm 1 \cdot 4$ & $2 \cdot 4 \pm 2 \cdot 3$ & $3 \cdot 0 \pm 1 \cdot 6$ \\
\hline
\end{tabular}

${ }^{*} \mathrm{p}<0.01$ from a Student's two-tailed $t$ test of the average difference between the IOP before and after surgery when compared with no change (i.e., $0 \cdot 0 \pm 0 \cdot 0)$. This is a paired $t$ test.

\section{Discussion}

Patients receiving sodium hyaluronate had a marked ocular hypertensive response during the first day and a half postoperatively when compared with preoperative values (Figs. 1 and 2 and Table 2). The maximum IOP occurred around 16 hours postoperatively. In a hyaluronate study using rabbits and cynomolgus monkeys the IOP was shown to peak at approximately three hours, ${ }^{12}$ probably reflecting species, age, or experimental differences. The aetiology of the ocular hypertension probably involves the large molecules of hyaluronate creating mechanical resistance in the trabecular meshwork. In a study of enucleated human eyes hyaluronate was found to cause a marked decrease in outflow facility..$^{13}$ Hyaluronidase is normally present in the anterior segment, ${ }^{14}$ but it appears to have only a negligible role because of the large amount of hyaluronate forced into the trabecular meshwork.

Ocular hypertension associated with cataract surgery is well documented..$^{15-19} \mathrm{Kirsch}^{15}$ found the incidence of increased IOP (Schiotz $>24.4 \mathrm{mmHg}$ ) in $72.5 \%$ of patients undergoing intracapsular cataract surgery with alpha-chymotrypsin (as used in the present study) compared with only $23.6 \%$ of patients not receiving the enzyme. The course of the 'enzyme' glaucoma was described typically from days 2 to 5 with recovery by day 7 . Actual clogging of the trabecular meshwork with zonular fragments has been reported in eyes treated with alphachymotrypsin. ${ }^{16}$ Extracapsular cataract extraction may be accompanied by lens debris in the anterior chamber, which may mix with hyaluronate and cause ocular hypertension. Our current method of cataract surgery is an extracapsular extraction with insertion of a posterior chamber lens. It is our clinical impression that postoperative intraocular pressures are higher than we previously observed following intracapsular cataract surgery. Even in patients receiving only saline (i.e., receiving neither alphachymotrypsin nor hyaluronate) ocular hypertension was observed as early as six hours after cataract surgery. ${ }^{17}$ This has also been observed by others, with IOPs reported to be greater than $30 \mathrm{mmHg} .{ }^{18}$ Implicated mechanisms include swelling of the trabecular meshwork and breakdown of the bloodaqueous barrier. ${ }^{120}$ These reactions would suggest that the usually observed ocular hypertension follow-
Fig. 2 Mean difference between the IOP at each time after surgery and its preoperative control value for the air (triangles), hyaluronate (circles), and hyaluronate plus acetazolamide $(X s)$ groups. The $S E$ for each point is given in Table 2.

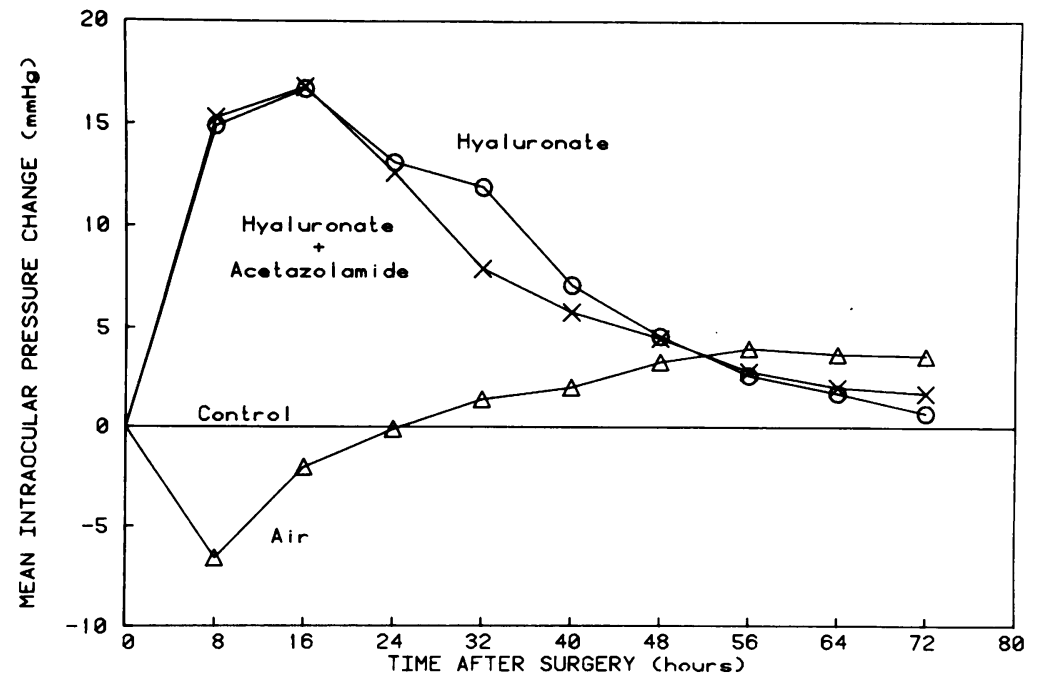


ing cataract surgery may be aggravated by the use of hyaluronate.

The present data revealed an initial, transient ocular hypotension in the patients receiving air (Figs. 1 and 2 and Table 2). This may have resulted from the direct effect of air or, possibly, from the relatively long operating times of resident surgeons who performed all the surgery. Long operating times may have caused mild choroidal detachments and hypotony. Brown et al. ${ }^{21}$ measured the IOP three hours after cataract surgery in 20 eyes that had received alpha-chymotrypsin and had an air bubble left in their anterior chambers. Their results are suggestive of an early decrease in the IOP (measured at three hours postoperatively). Air, a compressible substance that is absorbed slowly over several days, may damage the endothelium, but the effect appears to be short-lived. ${ }^{22}$ It may be that a combination of hyaluronate and air would neutralise the IOP changes, though surgical visualisation is decreased when air mixes with hyaluronate.

The unique physiochemical nature of hyaluronate probably negates the therapeutic value of agents that reduce aqueous secretion (e.g., acetazolamide). Removal of excess hyaluronate prior to closure may prove to be of value, although it did not alleviate the outflow blockage in enucleated eyes filled with hyaluronate. ${ }^{13}$ No increase in morbidity was evident in our patients, but the potential for ischaemic retinal and optic disc disease is real. Although hyaluronate is extremely useful in intraocular surgery, we believe that further studies are important to develop appropriate treatment for the raised IOP in patients receiving it.

The patients were all operated on at the Wishard Memorial Hospital, Indianapolis, Indiana, between September 1980 and February 1981. The authors would like to thank John O'Riordan for his advice and assistance with the statistical analyses. This investigation was supported in part by National Eye Institute research grant EY 04085 and a Research to Prevent Blindness research grant professorship (JTE).

\section{References}

1 Balazs EA, Freeman MI, Kloti R, Meyer-Schwickerath G, Regnault F, Sweeney DB. Hyaluronic acid and replacement of vitreous and aqueous humour. Mod Probl Ophthalmol 1972; 10: 3-21.

2 Grace EL, Polack FM, Balazs EA. The protective effect of Nahyaluronate to corneal endothelium. Exp Eye Res 1980; 31: 119-27.

3 Miller D, Stegmann R. Use of Na-hyaluronate in anterior segment eye surgery. Am Intra-Ocular Implant Soc J 1980; 6: 13-5.

4 Pape LG, Balazs EA. The use of hyaluronate (Healon) in human anterior segment surgery. Ophthalmology (Rochester) 1980; 87: 699-705.

5 Binkhorst $\mathrm{CD}$. Inflammation and intraocular pressure after the use of Healon in intraocular lens surgery. Am Intra-Ocular Implant Soc J 1980; 6: 340-1.

6 Lazenby GW, Broocker G. The use of sodium hyaluronate (Healon) in intracapsular cataract extraction with insertion of anterior chamber intraocular lenses. Ophthalmic Surg 1981; 12: 646-9.

7 Percival SPB. Complications from use of sodium hyaluronate (Healonid) in anterior segment surgery. Br J Ophthalmol 1982; 66: 714-6.

8 Holmberg AS, Philipson BT. Sodium hyaluronate in cataract surgery: I. Report on the use of Healon in two different types of intracapsular cataract surgery. Ophthalmology (Rochester) 1984; 91: 45-52.

9 Holmberg AS, Philipson BT. Sodium hyaluronate in cataract surgery: II. Report on the use of Healon in extracapsular cataract surgery using phacoemulsification. Ophthalmology (Rochester) 1984; 91: 53-9.

10 Polack FM, Demong T, Santaella H. Sodium hyaluronate (Healon) in keratoplasty and IOL implantation. Ophthalmology (Rochester) 1981; 88: 425-31.

11 Smith JA, Anderson DR. Effect of the intraocular lens on intraocular pressure. Arch Ophthalmol 1976; 94: 1291-4.

12 MacRae SM, Edelhauser HF, Hyndiuk RA, Burd EM, Schultz RO. The effects of sodium hyaluronate, chondroitin sulfate and methylcellulose on the corneal endothelium and intraocular pressure. Am J Ophthalmol 1983; 95: 332-41.

13 Berson FG, Patterson MM, Epstein DL. Obstruction of aqueous outflow by sodium hyaluronate in enucleated human eyes. $\mathrm{Am} \mathrm{J}$ Ophthalmol 1983; 95: 668-72.

14 Hayasaka S, Sears ML. Distribution of acid phosphatase, B-glucuronidase, and lysosomal hyaluronidase in the anterior segment of the rabbit eye. Invest Ophthalmol Visual Sci 1978; 17: 982-7.

15 Kirsch RE. Glaucoma following cataract extraction associated with use of alpha-chymotrypsin. Arch Ophthalmol 1964; 72: 612-20.

16 Anderson DR. Experimental alpha-chymotrypsin glaucoma studied by scanning electron microscopy. Am J Ophthalmol 1971; 71: 470-6.

17 Rich WJ, Radtke ND, Cohan BE. Early ocular hypertension after cataract extraction. Br J Ophthalmol 1974; 58: 725-31.

18 Haimann MH, Phelps CD. Prophylactic timolol for the prevention of high intraocular pressure after cataract extraction. Ophthalmology (Rochester) 1981; 88: 233-8.

19 Packer AJ, Fraioli AJ, Epstein DL. The effect of timolol and acetazolamide on transient intraocular pressure elevation following cataract extraction with alpha-chymotrypsin. Ophthalmology (Rochester) 1981; 88: 239-43.

20 Sears D, Sears M. Blood-aqueous barrier in alpha-chymotrypsin glaucoma in rabbits. Am J Ophthalmol 1974; 77: 378-83.

21 Brown SVL, Tye JG, McPherson SD jr. Intraocular pressure after intracapsular cataract extraction. Ophthalmic Surg 1984; 15: 389-93.

22 Lang RM, Hassard DTR. Effects on corneal endothelium of anterior chamber reconstituents instilled during intracapsular cataract extraction. Can J Ophthalmol 1981; 16: 70-2. 